\title{
Influence of the embryo on the distribution of maternal immunoglobulins in the mouse uterus
}

\author{
F. Rachman*, V. Casimiri $\dagger$, A. Psychoyos $†$ and O. Bernard* \\ *Unité de Recherche d'Hépatologie Infantile, INSERM U 56, Hôpital de Bicêtre, and $\uparrow$ Laboratoire \\ de physiologie de la Reproduction, ER 203 CNRS, Hôpital de Bicêtre (Bât. INSERM), \\ F-94270 Bicêtre, France
}

\begin{abstract}
Summary. The effect of the embryo on the distribution of $\operatorname{IgA}, \operatorname{IgG}$ and $\operatorname{IgM}$ was studied by an immunoperoxidase technique on mouse uterine sections, (1) during the first part of pregnancy and pseudopregnancy, and (2) in delayed implantation combined with different progesterone-oestradiol treatments designed to extend the delay or induce implantation, and in nonpregnant ovariectomized mice similarly treated. The number of glandular lumina containing IgA increased particularly from the implantation period, but in pseudopregnancy this number decreased from the morning of Day 4 , and afterwards continued to decline. In delayed implantation, the number of glandular lumina containing IgA also rose considerably when implantation was induced by oestradiol, whereas under the same progesterone-oestradiol treatment, nonpregnant ovariectomized animals displayed no such increase. Significant staining for IgG in the stroma was observed on Day 4 of pregnancy and pseudopregnancy but prolonged staining for IgG was observed only during pregnancy. In addition, significant numbers of IgA-plasma cells in the stroma were observed mostly in uteri containing embryos. These results indicate that embryos might affect the process by which ovarian hormones regulate $\mathrm{IgA}$ and $\mathrm{IgG}$ distribution.
\end{abstract}

\section{Introduction}

Evidence has accumulated that, in the female genital tract, the presence of certain lymphocytes and immunoglobulins might be regulated by ovarian hormones. Stimulation by oestradiol and down regulation by progesterone have been described in rodents during the oestrous cycle or after ovariectomy and hormonal treatment (Wira \& Sandoe, 1977, 1980; Wira, Hyde, Sandoe, Sullivan \& Spencer, 1980; Siiteri \& Stites, 1982; Canning \& Billington, 1983; Rachman, Casimiri, Psychoyos \& Bernard, 1983). Nevertheless, in mice, the stimulation of IgA and IgG secretion in uterine tissue and lumen during pregnancy starts during the implantation period and persists for at least the first part of pregnancy (Bernard, Ripoche \& Bennett, 1977; Bernard, Rachman \& Bennett, 1981; Rachman, Casimiri \& Bernard, 1984). During this period, plasma oestradiol concentration rises briefly and then declines to low levels, whereas the progesterone concentration increases and remains high (McCormack \& Greenwald, 1974). It is therefore possible that, in pregnant mice, ovarian hormones may not be entirely responsible for controlling the mechanisms that regulate immunoglobulin secretion in the uterus, and that the embryo may also affect these processes. We report here the distribution of $\operatorname{IgG}, \operatorname{IgA}$ and $\operatorname{IgM}$ in the mouse uterus under various experimental conditions in the presence of the embryo or in its absence. Early pregnancy was compared in this respect to pseudopregnancy. This last situation allows the influence of the embryo to be eliminated and preserves an hormonal status similar to that of early pregnancy (Brown-Grant, Corker \& Naftolin, 1972; Yoshinaga, 1973; Pepe \& Rothchild, 1974). In addition, a group of mice undergoing a delay in implantation (ovariectomized early in pregnancy and daily treated with 
progesterone to maintain the delay) were compared with mice which under the same delay conditions were given a single nidatory-dose of oestradiol (Psychoyos, 1973). The two groups were also compared to corresponding groups of nonpregnant ovariectomized mice similarly treated. This procedure made it possible to distinguish the role of the embryo in controlling immunoglobulin distribution from that of the ovarian hormones.

\section{Materials and Methods}

Animals. Mice of the OF1 (random-bred) as well as BALB/c strains were used. They were kept under standard animal house conditions on a $14 \mathrm{~h}$ light: $10 \mathrm{~h}$ darkness schedule. Virgin females of 8-12 weeks of age were used and were mated with males of the same strain when necessary. Day 1 of pregnancy was the day on which a vaginal plug was found.

Pregnant mice. Previous experiments (Bernard et al., 1981; Rachman et al., 1984) were repeated and extended to permit comparisons with the new experimental procedures. Groups of pregnant females were thus killed daily from Days 2 to 9 and also at 3.5 and 4.5 days as previously described (Bernard et al., 1981).

Pseudopregnant mice. Females were left overnight with 5-month-old males vasectomized 3 months earlier and of proven sterility. Day 1 of pseudopregnancy was the day on which a vaginal plug was found. Mice were killed daily from Days 2 to 9 , and also at 3.5 and 4.5 days.

Females undergoing delayed implantation. Females were mated with males aged 3 months. Experimentally delayed implantation was obtained by bilateral subcapsular ovariectomies on Day 2 of pregnancy, leaving the oviduct intact, and by daily s.c. injection of $2 \mathrm{mg}$ progesterone (Sigma, St Louis, MO, U.S.A.) in sesame oil. Implantation was induced on Day 8 by a single s.c. injection of $0.15 \mu \mathrm{g}$ oestradiol (Sigma) combined with progesterone treatment. Mice were killed 4, 9 or $26 \mathrm{~h}$ after oestradiol administration. The control group, which was not given oestradiol, was also killed on Day 8. To determine whether the eggs were in the process of implantation, $0.25 \mathrm{ml} 1 \%$ Pontamine Sky blue in $0.9 \%(\mathrm{w} / \mathrm{v}) \mathrm{NaCl}$ (Psychoyos, 1973) was injected $15 \mathrm{~min}$ before killing. As expected, only the females killed $26 \mathrm{~h}$ after oestradiol injection exhibited blue-stained spots. The mean number of blue spots was $4 /$ uterine horn. None of the other females undergoing delayed implantation displayed any blue spots. In each of these females, one horn was therefore flushed to confirm the presence of blastocysts.

Nonpregnant ovariectomized mice. Bilateral ovariectomies were performed the day after oestrus and, 5 days later, mice in one group were given a daily s.c. injection of $2 \mathrm{mg}$ progesterone. On Day 8 of progesterone treatment, these mice were also given a single s.c. injection of $0.15 \mu \mathrm{g}$ oestradiol and killed 4, 9 or $26 \mathrm{~h}$ afterwards. Mice in the other group were also killed on Day 8 of progesterone treatment but did not receive oestradiol.

General procedures. Animals were anaesthetized by i.p. injection of $0.2 \mathrm{ml}$ per g body weight of a 1-2\% solution of tribromoethanol (Avertin: Aldrich -...Europe) dissolved in iso-amyl-alcohol.

Tissue preparation and immunoperoxidase staining techniques. In each group, IgA, IgG and IgM distribution was examined in uterine horns from 4-6 mice for each period studied. Mice were killed by cervical dislocation. After ligation and sectioning at both ends, uterine horns were treated as previously described (Bernard et al., 1981). Briefly, each horn was fixed in 4\% buffered paraformaldehyde and embedded in polyethylene glycol 1000 . Sagittal sections $(5 \mu \mathrm{m})$ were incubated for $30 \mathrm{~min}$ with a $1 / 20$ dilution of rabbit anti-mouse IgA, IgG or IgM (Litton: Bionetics, Kensington, MD) and then for $30 \mathrm{~min}$ with a 1/20 dilution of peroxidase-labelled sheep Fab anti-rabbit immunoglobulin adsorbed with mouse immunoglobulin (Institut Pasteur Production, Paris, and Biosys, Compiègne, France). Sections were stained with diaminobenzidine and hydrogen peroxide. The presence of immunoglobulin was shown by a brown deposit. The following verifications were 
carried out. (1) Sections were incubated in PBS, instead of peroxidase conjugate, to detect endogenous peroxidase activity. (2) Sections were incubated with specific antisera and each of their corresponding antigens (purified mouse myeloma IgG, IgA and IgM from Bionetics Laboratories), instead of specific antisera alone. Staining was not altered by coincubation of the antiserum with unrelated immunoglobulin, but was suppressed by coincubation of the antiserum with the corresponding immunoglobulin. (3) Positive controls for each immunoglobulin antiserum were obtained on sections of mouse iliac lymph nodes.

Quantitation of glands and plasma cells containing immunoglobulins. IgA, IgG and IgM plasma cells were counted in each sagittal section of whole uterine horns. The numbers of such plasma cells observed during pregnancy and pseudopregnancy were compared between Days 2 and 6 of pregnancy only, because after this stage the embryonic capsule prevents their accurate enumeration in the adjacent uterine tissue. All the glandular lumina, whether or not they contained immunoglobulins, were individually counted in each sagittal section of the whole uterine horn. Statistical analysis was done by Student's $t$ and Mann-Whitney tests.

\section{Results}

Mice of the OFl (random-bred) and BALB/c strains gave similar results.

\section{Pregnant mice}

$\operatorname{Ig} A$. The mean number of uterine glands containing IgA rose markedly from Day $4(P<0.005)$ and remained high until Day 9 (average $70 \%)$ except for a significant drop at 4.5 days $(P<0.01)$ (Fig. 1a). IgA granules were also always seen from Day 4 in the glandular epithelium. In the uterine lumen, the presence of $\operatorname{IgA}$ was always observed from Day 6, while IgA granules were irregularly detected in the luminal epithelium on Days 6 and 7. Faint IgA staining was seen in the stroma on Days 6 and 7 only. Mean number of IgA-plasma cells increased significantly from Day $4(P<0.03)$ (Fig. 2).

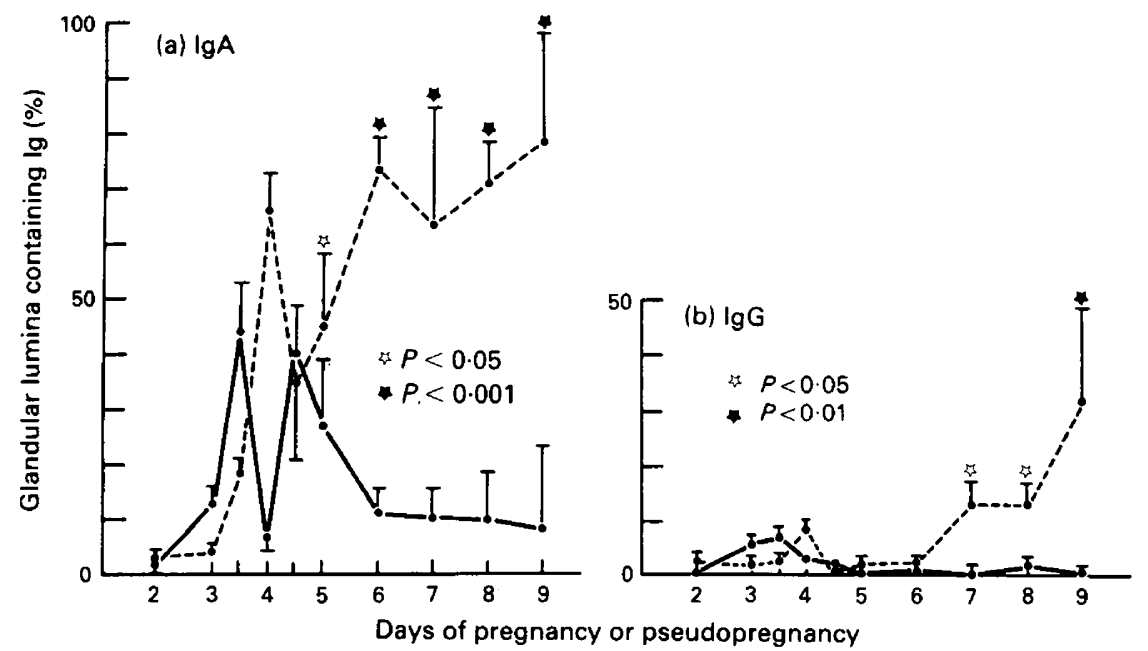

Fig. 1. Influence of pregnancy (-- $)$ and pseudopregnancy $(-)$ on the number of glandular lumina containing IgA (a) and IgG (b) in the mouse uterus. From Day 5, mean IgA values were significantly higher in pregnancy than in pseudopregnancy. In both situations, mean IgG values were not significantly different until Day 6 . At Days 7,8 and 9 , they increased significantly in pregnancy, but were almost nil in pseudopregnancy. 


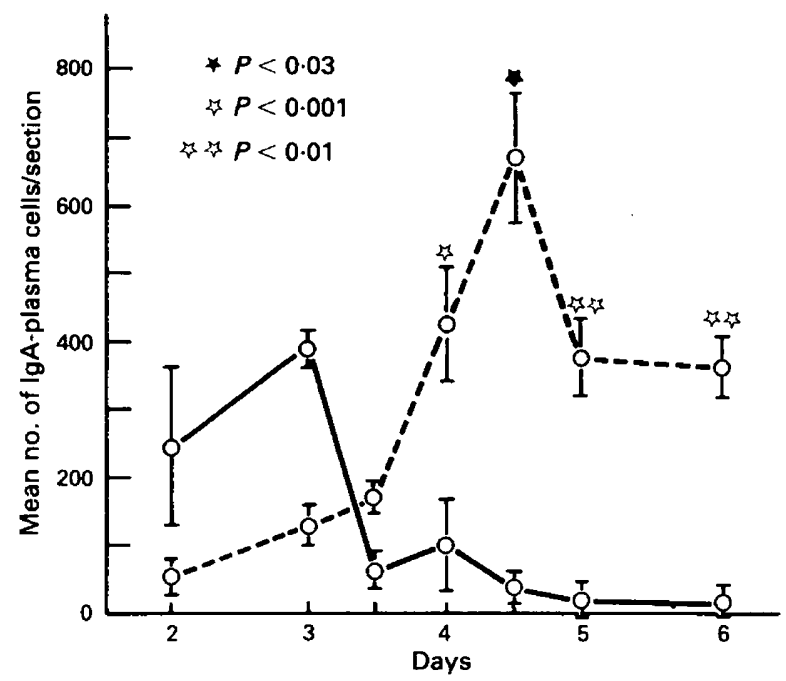

Fig. 2. Time course of the appearance of IgA-plasma cells in the uterus during pregnancy $(---)$ and pseudopregnancy (-). From Day 4, comparison of these two groups showed significant higher mean numbers during pregnancy.

$\operatorname{IgG}$. Staining for IgG was extensive in the stroma from Day 4.5 only. In the uterine glands, slight persistent secretion was observed from Day 6, after a small rise on Day 4 (Fig. Ib). However, no IgG was seen in the glandular epithelium. In the uterine lumen, IgG was always noted from Day 6, and a few IgG granules were visible in the luminal epithelium on Day 6. A few IgG-plasma cells (fewer than 10/section) were always seen from Day 3.

$\operatorname{Ig} M$. IgM was detected only in blood vessels.

\section{Pseudopregnant mice}

$\operatorname{Ig} A$. The mean percentage of uterine glands containing $\operatorname{IgA}$ was highest at 3.5 days, 4.5 days and 5 days and then decreased to low levels (Fig. 1a). IgA cytoplasmic granules were visible in a few cells of the glandular epithelium from Days 3 to 5 . In the uterine lumen, IgA secretion was occasionally observed on Days 3 and 3.5 and was slight from Day 6, while no IgA granules were detected in the uterine epithelium. A large number of IgA-plasma cells was observed on Days 2 and 3 but dropped significantly from Day $3.5(P<0.03)$ (Fig. 2$)$.

$\operatorname{IgG}$. Fewer than $10 \%$ of the glands were observed to contain IgG between Days 3 and 4 (Fig. 1b). IgG granules were never observed in the glandular epithelium. Staining for IgG in the stroma was extensive during the first 3 days, but none was seen afterwards. Such staining was scarcely detectable on Days 2, 3 and 8 in the uterine lumen, and was never seen in the uterine epithelium. Very few IgG-plasma cells were observed on Days 2 and 3 and not at all after that.

IgM. The uterine tissue never contained IgM except for blood vessels.

\section{Delayed implantation}

$\operatorname{Ig} A$. A significantly higher mean percentage of glandular lumina containing $\operatorname{IgA}$ was observed between 4 and $9 \mathrm{~h}(P<0.01)$. No significant difference was noted between 9 and $26 \mathrm{~h}$ (Fig. 3). In the mice given progesterone only, a large number of IgA-plasma cells was found, mostly round the uterine glands. No IgA was observed in their lumina and epithelium. Only occasional IgA staining was seen in the uterine lumen and very few IgA granules in the luminal epithelium. In the animals 
given oestradiol, $50 \%$ of glands contained IgA at $26 \mathrm{~h}$ (Fig. 3a), and a few IgA granules appeared in the glandular epithelium. The stroma and uterine lumen and epithelium were always virtually devoid of IgA. IgA-plasma cells were always present (Fig. 4) but their number decreased $9 \mathrm{~h}$ after oestradiol injection $(P<0.03)$ (Fig. 5).

$\operatorname{Ig} G$. Whatever the hormonal treatment, staining for IgG was never observed in the uterine glandular lumina and epithelium. At $26 \mathrm{~h}$ after oestradiol injection, the uterine lumen sometimes displayed faint IgG staining but this was never seen in the luminal epithelium. In the stroma, staining was rare. A few IgG-plasma cells were only seen in the group not given oestradiol treatment $(10 \pm 4 /$ section $)$.

$\operatorname{Ig} M$. This immunoglobulin was never observed outside the blood vessels.

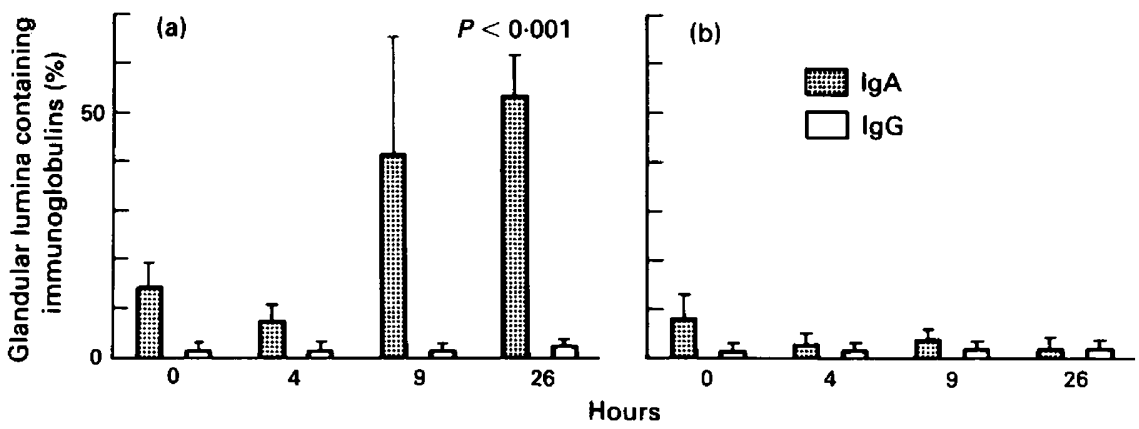

Fig. 3. Time course of the effect of a single dose injection of oestradiol on uterine glandular lumina containing IgA and IgG in mice undergoing delayed implantation (a) and in nonpregnant ovariectomized mice (b). Comparison of groups (a) and (b) indicates that mean $\operatorname{IgA}$ percentages rise significantly between 4 and $26 \mathrm{~h}$ only in group (a). No significant difference was observed in mean IgG between group (a) and (b).

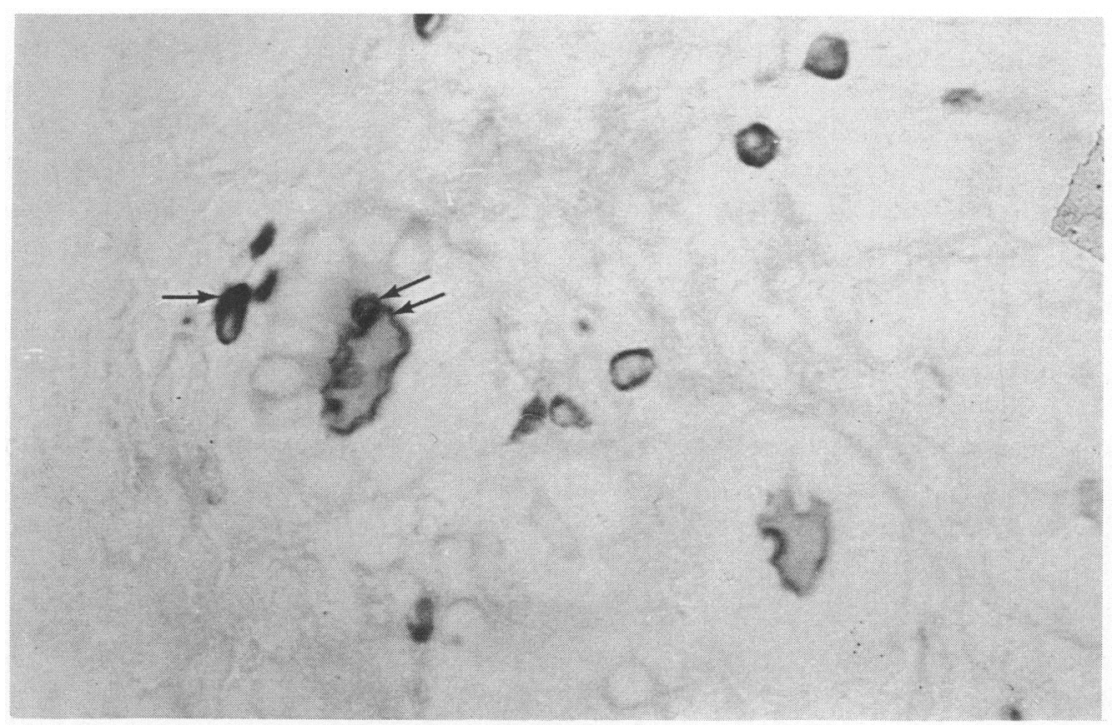

Fig. 4. Delayed implantation. Presence of IgA-plasma cells $(\rightarrow)$ round uterine glands containing IgA secretion $(\rightrightarrows) 4 \mathrm{~h}$ after oestradiol injection. (Indirect immunoperoxidase localization; $\times 250$.) 


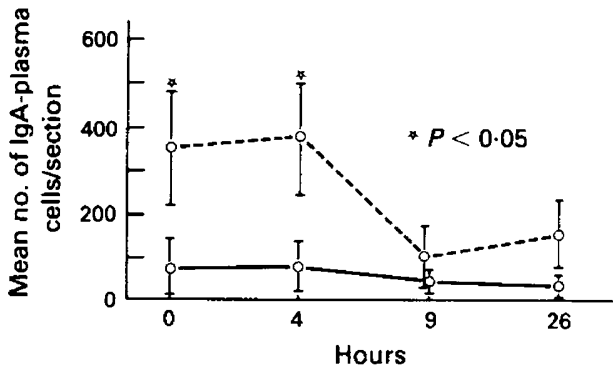

Fig. 5. Time course of the appearance of IgA-plasma cells in the uterus after oestradiol injection during delayed implantation ( - - ) and nonpregnant ovariectomized mice $(-)$. The comparison of these two groups showed a significant higher mean number of IgA-plasma cells in the delayed implantation group only until $4 \mathrm{~h}$ after oestradiol injection.

\section{Nonpregnant ovariectomized mice}

$\operatorname{Ig} A$. Whatever the hormonal treatment mean number of $\operatorname{IgA}$-containing glands was always small and never varied significantly (Fig. 3b). No IgA was ever noted in the glandular epithelium. In the uterine lumen, occasional staining was seen in the groups not given oestradiol, and also $26 \mathrm{~h}$ after oestradiol injection. A few granules were detected in the luminal epithelium in the groups without oestradiol. In all groups, the stroma was practically devoid of IgA and the number of IgA-plasma cells was always small and never varied significantly (Fig. 5).

$\operatorname{IgG}$. The mean percentages of uterine glandular lumina containing IgG were always low and never varied significantly. No IgG was ever found in the glandular epithelium or lumina or in the stroma. The uterine lumen exhibited slight staining in groups without oestradiol only, but the luminal epithelium never stained. No IgG-plasma cells were observed.

$\operatorname{Ig} M$. Only blood vessels stained for IgM.

\section{Discussion}

The present results underline the influence of the embryos on the secretion in the mouse uterus of $\operatorname{IgA}$ and IgG but not of IgM. From our study it appears considerable variations occur in the mouse uteri under the same hormonal conditions according to the presence or the status of embryonic activity. As shown here in delayed implantation, the number of glandular lumina containing $\operatorname{IgA}$ rose considerably with time when oestradiol injection was added to the progesterone treatment.

It is well established that the hormonal treatment used here induces implantation in mice undergoing a delay (Humphrey, 1967; Psychoyos, 1973). In the nonpregnant ovariectomized animals investigated here, no detectable stimulation of immunoglobulin secretion was observed with the same hormonal schedule. Consequently, the implanting embryos seemed to be involved in IgA distribution in the uterine glands. Moreover, the results obtained for pregnant and pseudopregnant mice showed marked changes from the implantation period. For example, the number of glandular lumina containing IgA rose similarly in both groups until the implantation period but then continued to rise only in pregnant mice with implanted embryos. In the pseudopregnant group, the number of these lumina dropped sharply on the morning of Day 4, and continued to decline thereafter after a brief rise at the end of Day 4. These results suggest that the persistence of IgA secretion might be correlated to the presence of activated blastocysts. In addition, the development of the implanted embryos seemed to maintain the immunoglobulin secretion.

The data obtained for IgG further support the hypothesis that the embryo might modulate immunoglobulin distribution. The small amount of IgG observed in the uterine stroma during the first days of pregnancy, and its massive diffusion from Day 4 (the day of implantation), contrasts 
with the opposite situation found in pseudopregnancy. This contrast might be due to the increased vascular permeability observed in pregnancy at the time of implantation (Psychoyos, 1960) which might have promoted the passive diffusion of IgG observed in the stroma from Day 4. Our previous findings suggested that IgG enters the stroma from the local capillaries (Rachman et al., 1983). However, the reason for the presence of IgG in the stroma during the first 3 days of pseudopregnancy remains unclear, and needs further investigation. In addition, we were unable to detect any IgG in the stroma of females at the end of the period of delay, just before implantation was induced by oestradiol. Sullivan \& Wira (1983) have demonstrated that the rapid increases observed in tissue levels of IgA and IgG after giving high doses of oestradiol to nonpregnant ovariectomized rats were dose-dependent; low doses of this hormone proved ineffective. In agreement with their data, the present results show that a similarly low dose of oestradiol did not induce IgA glandular secretion in nonpregnant ovariectomized mice, but, $9 \mathrm{~h}$ after oestradiol injection, markedly enhanced this secretion in mice undergoing delayed implantation. This increase continued until $26 \mathrm{~h}$ after treatment. Our findings indicate that stimulation of IgA secretion by a low dose of oestradiol not only necessitates priming by progesterone to induce uterine sensitivity (see Psychoyos, 1973) but also that it depends on the presence of embryos. The mechanisms by which the embryo might stimulate immunoglobulin secretion are at present uncertain. During the oestrous cycle and after ovariectomy followed by progesterone and oestradiol treatment, it was observed that IgA B lymphocyte migration is ovarian hormone-dependent: progesterone alone, or associated with oestradiol, acting as inhibitor, and oestradiol as stimulator (Wira \& Sandoe, 1980; Canning \& Billington, 1983). However, the present results show that, in animals undergoing delayed implantation, a significantly large number of IgA-plasma cells were found in the stroma of females which had been given progesterone alone or, in addition, had been injected with oestradiol $4 \mathrm{~h}$ before sampling, compared to nonpregnant ovariectomized animals similarly treated. In pregnancy, the number of plasma cells in the uterus also rose with the level of plasma progesterone.

These findings suggest that hormonal regulation of lymphocyte migration is modified when the uteri bear embryos, whether they are dormant or implanted. Embryos might therefore affect immunoglobulin secretion through lymphoblast migration to the endometrium. The similar results observed in mice of inbred and outbred matings do not suggest, at least from a morphological view point and for a first mating, that allogeneic or syngeneic embryos have significantly different effects on immunoglobulin secretion in the uterus.

We thank Mme Grelier and Mme R.-M. Dreyfus for help with the preparation and revision of the manuscript. The work was supported by CNRS No. 03.3676 and UER Kremlin-Bicêtre No. 867.

\section{References}

Bernard, O., Ripoche, M.A. \& Bennett, D. (1977) Distribution of maternal immunoglobulins in the mouse uterus and embryo in the days after implantation. J. exp. Med. 145, 58-75.

Bernard, O., Rachman, F. \& Bennett, D. (1981) Immunoglobulins in the mouse uterus before implantation. J. Reprod. Fert. 63, 237-240.

Brown-Grant, K., Corker, G.S. \& Naftolin, F. (1972) Plasma and pituitary luteinizing hormone concentrations and peripheral plasma oestradiol concentration during early pregnancy and after the administration of progestational steroids in the rat. J. Endocr. 53, 31-35.
Canning, M.B. \& Billington, W.D. (1983) Hormonal regulation of immunoglobulins and plasma cells in the mouse uterus. J. Endocr. 97, 919-924.

Humphrey, K.W. (1967) The induction of implantation in the mouse after ovariectomy. Steroids 10, 591-600.

McCormack, J.T. \& Greenwald, G.S. (1974) Progesterone and oestradiol-17\% concentrations in the peripheral plasma during pregnancy in the mouse. J. Endocr. 62, 101-107.

Pepe, G.J. \& Rothchild, I. (1974) A comparative study of serum progesterone levels in pregnancy and in various types of pseudopregnancy in the rat. Endocrinology 95, 275-279. 
Psychoyos, A. (1960) Nouvelle contribution à l'étude de la nidation de l'oeuf chez la rate. C. r. hebd. Séance Acad. Sci. Paris D 251, 3073-3075.

Psychoyos, A. (1973) Endocrine control of egg implantation. In Handbook of Physiology. Endocrinology: II. Vol. 2, pp. 187-215. Eds R. O. Greep \& E. B. Astwood. Am. Physiol. Soc., Washington, D.C.

Rachman, F., Casimiri, V., Psychoyos, A. \& Bernard, O. (1983) Immunoglobulins in the mouse uterus during the oestrous cycle. J. Reprod. Fert. 69, 17-21.

Rachman, F., Casimiri, V. \& Bernard, O. (1984) Maternal immunoglobulins $\mathbf{G}, \mathrm{A}$ and $\mathbf{M}$ in the mouse uterus and embryo during the postimplantation period. $J$. Reprod. Immunol. 6, 39-47.

Siiteri, P.K. \& Stites, D.P. (1982) Immunologic and endocrine interrelationship in pregnancy. Biol. Reprod. 26, 1-14.

Sullivan, D.A. \& Wira, C.R. (1983) Hormonal regulation of immunoglobulins in the rat uterus: uterine response to a single estradiol treatment. Endocrinology 112, 260-268.
Wira, C.R. \& Sandoe, C.P. (1977) Sex steroid hormone regulation of $\mathrm{IgA}$ and $\mathrm{IgG}$ in rat uterine secretion. Nature, Lond. 268, 534-535.

Wira, C.R. \& Sandoe, C.P. (1980) Hormonal regulation of immunoglobulins: influence of estradiol on immunoglobulins $A$ and $G$ in the rat uterus. Endocrinology 106, 1020-1026.

Wira, C.R., Hyde, E., Sandoe, C.P., Sullivan, D. \& Spencer, S. (1980) Cellular aspect of the rat uterine IgA response to estradiol and progesterone. $J$. Steroid Biochem. 12, 451-459.

Yoshinaga, K. (1973) Gonadotrophin-induced hormone secretion and structural changes in the ovary during the nonpregnant reproductive cycle. In Handbook of Physiology. Endocrinology: II, vol. 2, part 1, pp. 363-384. Eds R. O. Greep \& E. B. Astwood. Am. Physiol. Soc. Washington, D.C.

Received 27 September 1985 